\title{
OS IMPACTOS DO SETOR SUCROENERGÉTICO PARA A RELAÇÃO CAMPO E CIDADE EM MUNICÍPIOS DE PEQUENO PORTE: O CASO EM JOSÉ BONIFÁCIO, UBARANA E PLANALTO - SÃO PAULO/BRASIL
}

Lucas Pauli ${ }^{1}$

\section{Resumo}

A partir de 2003 o governo brasileiro retomou o incentivo ao setor sucroenergético, principalmente com o discurso dos agrocombustíveis como fonte de energia limpae sustentado pela comercialização de carros com a tecnologia Flex Fuel,com isso motivando um intenso processo de expansão dos canaviais e plantas industriais no estado de São Paulo, principalmente na porção oeste. A microrregião de São José do Rio Preto, no noroeste paulista, está dentre as que receberam mais plantas industriais e onde os canaviais mais se expandiram. O surgimento das grandes plantas industriais causou intensas alterações econômicas e sociais nos municípios, aumentando sobremaneira os postos de empregos, a massa salarial, o Produto Interno Bruto (PIB) e a arrecadação de impostos. É frente a este quadro que o artigo se centra em analisar como esse processo impactou na relação campo e cidade nos municípios de Jose Bonifácio, Planalto e Ubarana que estão inseridos na microrregião de São José do Rio Preto. Neste sentido, compreendemos que o agronegócio possui papel basilar quanto à relação campo e cidade nos municípios selecionados, pois possui papel dinamizador entre os dois espaços.

Palavras-chaves: Setor Sucroenergético, relação campo e cidade, Microrregião de São José do Rio Preto

\section{THE IMPACTS OF THE SUGAR-ENERGY SECTOR ON THE RURAL- URBAN RELATIONSHIP IN SMALL MUNICIPALITIES: THE CASE OF JOSÉ BONIFÁCIO, UBARANA AND PLANALTO-SÃO PAULO/BRAZIL}

\begin{abstract}
From 2003 the Brazilian government resumed the incentive to the sugar-energy sector, mainly with the discourse of agrofuels as a source of clean energyand supported by the commercialization of cars with the Flex Fuel technology, thus motivating an intense process of expansion of sugar cane and industrial plants in the state of São Paulo , Mainly in the western portion. The micro-region of São José do Rio Preto, in the northwest of São Paulo, is

\footnotetext{
${ }^{1}$ Mestrando em Geografia pelo Programa de Pós Graduação em Geografia na Faculdade de Ciências e Tecnologia da Universidade Estadual Paulista FCT/UNESP/Presidente Prudente. Bolsista FAPESP. E-mail: lucasppauli@hotmail.com.
}

Sociedade e Território - Natal. Vol. 27, N. 3, p. 123 - 141.Jan./Jun. de 2017 
among those that received more industrial plants and where the sugar cane plantations expanded more. The emergence of the large industrial plants caused intense economic and social changes in the municipalities, greatly increasing jobs, wages, Gross Domestic Product (GDP) and tax collection. It is against this background that the article focuses on analyzing how this process impacted the countryside and city relationship in the municipalities of Jose Bonifácio, Planalto and Ubarana that are inserted in the micro-region of São José do Rio Preto. In this sense, we understand that agribusiness has a basilar role in relation to the field and city in the selected municipalities, since it has a dynamic role between the two spaces.

Keywords: Sugar-energy sector, field and city relationship, Microregion of São José do Rio Preto

\section{LOS IMPACTOS DEL SECTOR SUCROENERGÉTICO PARA LA RELACIÓN CAMPO Y CIUDAD EN MUNICIPIOS DE PEQUEÑO PORTE: EL CASO EN JOSÉ BONIFACIO, UBARANA Y PLANALTO- SÃO PAULO/BRASIL}

\section{Resumen}

A partir de 2003 elgobiernobrasileñoretomóel incentivo al sector sucroenergético, principalmente conel discurso de losagrocombustibles como fuente de energíalimpiay sostenido por la comercialización de coches con la tecnología Flex Fuel, con ello motivando un intenso proceso de expansión de los cañaverales y plantas industriales en el estado de São Paulo Principalmente en la porción oeste. La microrregión de San José del Río Negro, en el noroeste paulista, está entre las que recibieron más plantas industriales y donde los cañaverales más se expandieron. El surgimiento de las grandes plantas industriales causó intensas alteraciones económicas y sociales en los municipios, aumentando sobre todo los puestos de empleos, la masa salarial, el Producto Interno Bruto (PIB) y la recaudación de impuestos. Es frente a este cuadro que el artículo se centra en analizar cómo ese proceso impactó en la relación campo y ciudad en los municipios de Jose Bonifacio, Planalto y Ubarana que están insertos en la microrregión de San José del Río Negro. En este sentido, comprendemos que el agronegocio posee papel basilar como la relación campo y ciudad en los municipios seleccionados, pues posee papel dinamizador entre los dos espacios.

Palabras claves: Azúcar-Energy Sector, en comparación campo y la ciudad, Micro región de São José do Rio Preto

\section{Introdução}

O artigo versa apresentar e analisar alguns impactos gerados pelo avanço do setor sucroenergético nos municípios de José Bonifácio, Ubarana e Planalto localizados na porção Noroeste do estado de São Paulo para a relação campo e cidade, tendo em vista que o 
agronegócio pode gerar mudanças e impactos tanto no campo e cidade, Elias (2008) indica que:

\begin{abstract}
O desenvolvimento de uma gama extensa de novas relações entre o campo e as cidades deve-se à crescente integração do agronegócio ao circuito da economia urbana. Tal situação dá-se, principalmente, porque o agronegócio tem o poder de impor especializações territoriais cada vez mais profundas. A produção agrícola e agroindustrial intensiva exige que as cidades próximas ao campo se adaptem para atender às suas principais demandas, convertendo-as no seu laboratório, em virtude de fornecerem a grande maioria dos aportes técnicos, financeiros, jurídicos, de mãode-obra e de todos os demais produtos e serviços necessários à sua realização. Quanto mais modernas se tornam essas atividades, mais urbana se torna a sua regulação.
\end{abstract}

O recorte dos três municípios se dá pela implantação recente, especificamente, a partir do ano de 2007 de usinas de produção de Etanol/Açúcar e também pelo forte aumento da área plantada de cana-de-açúcar. A análise dos impactos será subsidia a partir de dados secundários coletados das seguintes bases de dados: IBGE-SIDRA; CANASAT. Partimos da evolução de indicadores econômicos e sociais para refletir sobre a existência de uma relação cidade ecampo a partir do avanço do setor sucroalcooleiro e seus impactos.

Sobreo tema relação cidade e campo / rural e urbano que permeia diversas áreas das ciências humanas, desde a sociologia rural a geografia, Alentejano (2003) atribui que:

[...] o debate acerca das relações campo cidade encontra-se numa encruzilhada. Diferentemente da segunda metade do século XX, quando o avanço, a generalização (e as vantagens) da urbanização eram considerados inexoráveis, o que se vê nos últimos anos é a proliferação de estudos que apontam para a e valorização do rural e as limitações do modelo de urbanização (ALENTEJANO, 2003, p.03).

A geografia começa a desempenhar relevância quando a discussão acima de tudo a partir da década de 1990, Alves (2012) salienta que isso se dá pela incorporação de um temário crítico e com perspectivas socioespaciais. JáHespanhol (2013) enfatiza que as mudanças ocorridas, principalmente as péssimas condições de vida nas cidades brasileiras tem elevado o campo a patamar de espaço de lazer e turismo fazendo perder a conotação dos espaços rurais serem apenas para o desenvolvimento de atividades agropecuárias, com isso surgem novas perspectivas de análise sobre as relações campo-cidade.

Alves (2012) e Hespanhol (2013) ressaltam três grandes abordagens sobre as definições de campo e cidade, rural e urbano. Sendo uma pautada na dicotomia entre os espaços, a do continuum e a de permanência das relações. 
Sobre a perspectiva dicotômica entre campo e cidade temos Sorokin, Zimmerman e Galpin (1986) como as principais referências. Os autores expõem nove diferenças entre campo e cidade sendo elas: Diferenças ocupacionais, diferenças ambientais, diferenças no tamanho das comunidades, diferenças na densidade populacional, diferenças na homogeneidade e na heterogeneidade das populações, diferenças na diferenciação, estratificação e complexidade social, diferenças na mobilidade social, diferença na direção da migração e diferenças no sistema de integração social. Notamos sempre uma oposição entre campo e cidade, constituindo uma visão setorial sobre o tema, no qual cabe a cada espaço uma característica estrita sem mudanças e não havendo interações ou trocas, Hespanhol (2013) destaca que:

No caso da realidade brasileira, a visão dicotômica foi dominante até os anos 1980 e, mesmo na atualidade, ela ainda esta presente em certas instituições, agências e políticas, sendo o espaço rural entendido de maneira restrita, ou seja, apenas como o local em que se realiza a produção agropecuária (HESPAPHOL, 2013, p.108).

Sobre a perspectiva de continuum sublinhamos que o processo de urbanização homogeneizaria o espaço rural conformando em um só espaço, não havendo mais uma dicotomia, essa noção está presente no projeto Rurbano de 1997 de José Graziano da Silva e na perspectiva do Novo Rural Brasileiro. Para Graziano (1997) o meio rural brasileiro se urbanizou nas duas últimas décadas, tendo em vista a industrialização da agricultura e que isso ocasionou no desparecimento das especificidades do rural ou até na sua extinção total. Dessa forma, Graziano (1997) atribui que: “o rural hoje só pode ser entendido como um "continuum" do urbano do ponto de vista espacial; e do ponto de vista da organização da atividade econômica, as cidades não podem mais ser identificadas apenas com a atividade industrial, nem os campos com a agricultura e a pecuária”. Para Abramovay (2000) o continuum "significa que não existem diferenças fundamentais nos modos de vida, na organização social e na cultura, determinadas por sua vinculação espacial”. Essa perspectiva ainda é importante dentro dos estudos sobre o tema.

A última perspectiva é a que se insere esse artigo que é a da permanência das relações. Alves (2012) considera que essa delimitação está para além dos ditames políticos administrativos e que o mais relevante são as relações e processos sociais no espaço. Já para Hespanhol (2013, p.109) "permanência de diferentes ruralidades derivadas das particularidades de cada lugar e da maneira como cada fração do espaço participa dos 
processos econômicos e sociais" é central para essa perspectiva de análise. Essa opção por analisar a relação cidade e campo vai totalmente contraria a do continuum, pois cada fração do território possui importância dentro dos processos, visto o desenvolvimento do capitalismo. A urbanização pode ter chegado ao campo, porém não extinguiu relações características desse espaço, por exemplo, o trabalho familiar que é elemento fundante para compreensão das sociedades rurais.

Contudo, o artigo parte de uma revisão bibliográfica sobre a relação cidade e campo e rural urbana no Brasil, depois apresenta alguns elementos do setor sucroenergético no estado de São Paulo e como impactou os municípios selecionados para análise.

\section{A RELAÇÃo CAMPO E CIDADE E RURAL E URBANO NO BRASIL: ALGUNS PRESSUPOSTOS}

A modernização da agricultura brasileira a partir da década de 60 resultou em diversas mudanças nos padrões de campo e cidade, principalmente a ideia de um rural atrasado em relação a cidade e apenas fundado na agricultura. A urbanização vivenciada no Brasil ao percurso do século XX também influenciou na relação campo e cidade, pois o paisdetinha um papel agrário-exportador, principalmente com o café, dessa maneira diminuindo os papeis urbanos das cidades, com o avanço da economia brasileira na década de 30 influenciado pela industrialização e com as políticas desenvolvimentistas iniciadas no governo Vargas. Wanderley (2009) destaca que:

\footnotetext{
No caso específico da sociedade brasileira, pelo menos três aspectos devem ser considerados, se queremos entender como a transformação mais global toma corpo na realidade social: a urbanização brasileira gerou uma enorme gama de pequenos municípios pouco "urbanos"; os setores industriais e de serviços permanecem ainda fortemente concentrados nas grandes cidades, apesar do movimento significativo de interiorização; a propriedade da terra permanece altamente concentrada (WANDERLEY, 2009, p.63).
}

Observamos no gráfico 1 um aumento gradativo da população urbana. Em 1970 acontece uma virada populacional, na qual a população urbana ultrapassa a população rural, Santos (1993, p.29) afirma que "Entre 1940 e 1980, dá-se verdadeira inversão quanto ao lugar de residência da população brasileira. Há meio século atrás (1940), a taxa de urbanização era de 26,35\%, em 1980 alcança 68,86\%1. Nesses quarenta anos, triplica a população total do Brasil, ao passo que a população urbana se multiplica por sete vezes e meia. "Isso se dá pelo 
êxodo rural proporcionado pela modernização do campo e outros elementos como aumento da natalidade e qualidade de vida da população urbana.

Gráfico 1: Evolução da população no Brasil

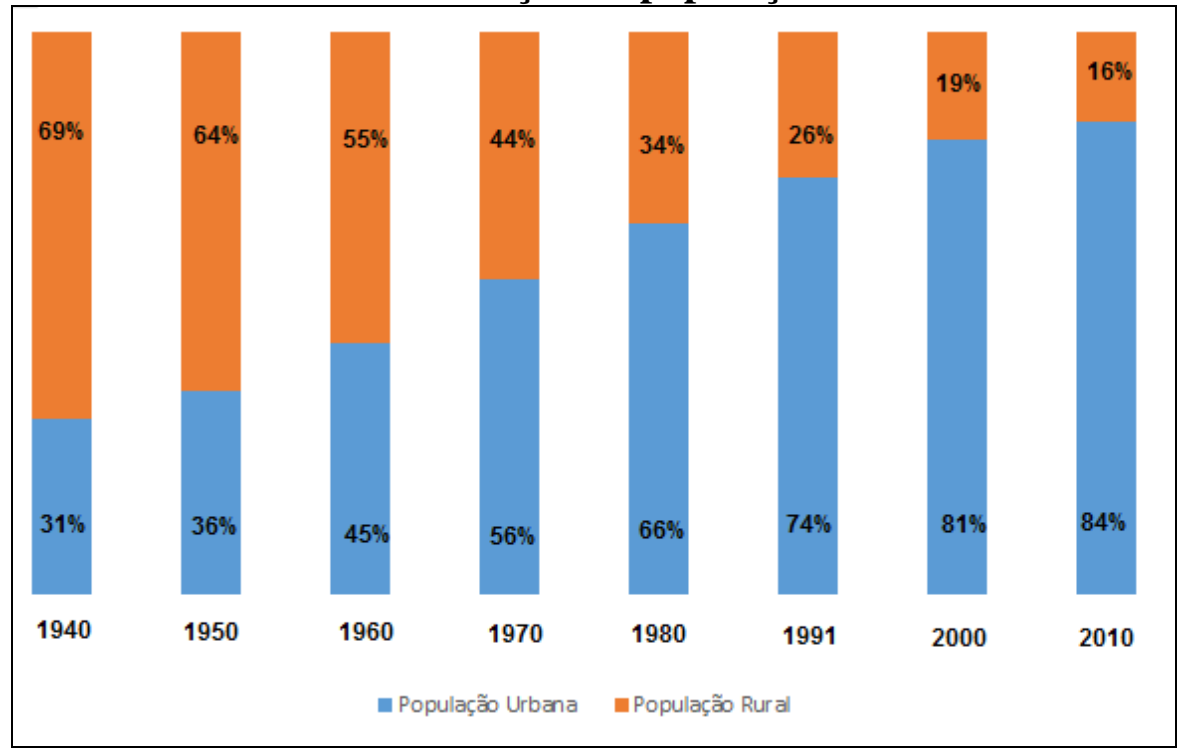

Fonte: Censo Demográfico - IBGE; Org: Pauli, L. 2016

Essa modernização se efetua segundo Delgado (1985) e Graziano da Silva (1996) a partir da mudança da base técnica da produção, tendo o Estado como indutor. Segundo Delgado (1985):

\begin{abstract}
Essa agricultura que se moderniza, sob o influxo dos incentivos do Estado e induzida tecnologicamente pela indústria, transforma profundamente sua base técnica de meios de produção. Esse processo significa, também, que, em certa medida a reprodução ampliada do capital no setor agrícola torna-se crescente integrada em termos de relações interindustriais para trás e para frente. No primeiro caso, essas relações implicam a própria mudança do processo de produção rural de forma articulada à indústria produtora de insumos (fertilizantes, defensivos e corretivos de solo) e de bens de capital (tratores, implementos diversos, colheitadeiras, equipamentos para irrigação etc.) (DELGADO, 1985, p.33).
\end{abstract}

Antes da consolidação da modernização da agricultura um elemento foi muito importa para isso, o Estatuto da Terra, segundo Martins ( 1985), o verdadeiro caráter do Estatuto da Terra é a função de controle das tensões sócias e dos conflitos gerados por esse processo de expropriação e concentração da propriedade e do capital, o Estatuto garante a partir das suas aplicações, desmobilizar os conflitos e garantir o desenvolvimento econômico baseado nos incentivos à progressiva e ampla penetração do grande capital agropecuário. Nessa perspectiva, Martins (1985) exprime que: 
O próprio Estatuto da Terra foi elaborado de tal forma que se orienta para estimular e privilegiar o desenvolvimento e a proliferação da empresa rural. O destinatário privilegiado do Estatuto não é o camponês, o pequeno lavrador apoiado no trabalho da família. O destinatário do Estatuto é o empresário, o produtor dotado de espírito capitalista, que organiza a sua atividade econômica segundo os critérios da racionalidade do capital. (MARTINS, 1985, p.33).

Dessa forma, é possível afirmar que o Estado brasileiro esteve presente nesse processo de modernização da agricultura, principalmente assegurando o credito para os investidores. A ideia de modernização está atrelada a industrialização do campo como um ramo da economia de produção e a incorporação do pacote da “Revolução Verde ${ }^{2 "}$.Hespanhol;Hespanhol (2006) apontam que:

A crescente incorporação de tratores, colheitadeiras, implementos agrícolas, fertilizantes e biocidas ao processo produtivo, liberaram grande quantidade de mãode-obra do campo, disponibilizando assim, força de trabalho para as atividades urbanas ao mesmo tempo em que deixou muita gente e à margem desse processo. (HESPANHOL; HESPANHOL, 2006, p.136).

Alguns autores, como Santos e Silveira (2001), afirmam que esse processo de modernização é o espaço sendo dotado de técnica, informação e ciência e se transformando no meio técnico cientifico informacional.Destacamos que a modernização do campo desdobrou também em melhorias das vias de transporte, pois é necessário o transporte da produção, desta maneira, resulta-se numa fluidez maior do território brasileiro, quebrando barreiras imposta e dinamizando o desenvolvimento do capitalismo em algumas regiões. Uma nova divisão territorial do trabalho é empregada a partir da modernização do campo resultando em novos papeis para o campo e a cidade.

Quanto à delimitação do que é urbano ou rural e campo ou cidade, partimos das perspectivas de Whitacker (2006) e Hespanhol (2013), que só a partir da dialético conseguimos analisar de forma ampla esses conceitos, visto formam um par, logo um par dialético. Devemos levar em conta que o campo e cidade são formas materializadas no espaço produzidas por relações sociais epossuem uma delimitação oficial mesmo duvidosa, como realizada pelo IBGE. Já urbano e rural constituem um processo não contidos necessariamente

\footnotetext{
${ }^{2}$ A revolução verde constituiu no avanço tecnológico da produção de sementes, fertilizantes e maquinários para o campo a partir da década de 50. Seu maior proposito era aumentar a produção e diminuição de custos.
} 
no espaço restrito a eles, por exemplo, relações típicas do campo na cidade, a produção de hortas ou criação de animais. Ou também relações vistas na cidade utilizadas no campo, como modo de falar e vestir. Locatel (2013, p.89) afirma que "Campo e cidade são construções sociais. São subespaços produzidos por relações sociais diferenciadas que, por sua vez, formam realidades diferenciadas, embora impulsionadas pela mesma lógica produtiva: a do modo de produção capitalista".

A principal definição de cidade no Brasil é a partir do Decreto-Lei 311 de 1938, sua função foi transformar em cidades todas as sedes urbanas municipais existentes. Segundo Veiga (2002)

\begin{abstract}
Até 1938 o Brasil não teve dispositivo legal que estabelecesse diferença entre cidade e vila. Era costume elevar à condição de vila, ou mesmo diretamente à condição de cidade, rústicas sedes de freguesia, a mais antiga unidade territorial brasileira. Vilas e cidades surgiam até sem previa existência de freguesias. Tanto cidades, quanto vilas, podiam ser sedes de município. $\mathrm{E}$ os limites geográficos de sua jurisdição eram demarcados pelos limites das freguesias, desde que se tratasse de espaço com ocupação consolidada (VEIGA, 2002, p.64).
\end{abstract}

É possível refletir sobre as afirmações feitas em Veiga (2002) que a delimitação utilizada pelo IBGE para conceber a cidade legalmente é um tanto obsoleta, visto todas as transformações ocorridas no Brasil a partir da década de 60 e também que toda sede de municípios seja urbana. Mas, a metodologia proposta pelo autor também é questionável, pois concentrar-se na ideia que diferencial essencialentre espaços urbanos e rurais poderiam ser mensuradas pela densidade demográfica, Sposito (2006, p.113) referente a questão da demografia como diferenciador entre cidade e campo, afirma que "Reconhecer uma parcela do território como urbana porque nela se observam determinados níveis de densidade habitacional, pode ser um ponto de partida, mas nunca o ponto de chegada para a análise. Neste sentido, devemos compreender a relação cidade e campo a partir do aporte espacial, visto o que os diferencia são os seus usos e consumos.

Wanderley (2009, p.64) destaca que o processo de urbanização no Brasil não foi uniforme, porém construiu uma rígida hierarquia urbana, comgrandes cidades metropolitanas até pequenas cidades com 20 mil habitantes, a autora questiona se essas pequenas cidades são propriamente urbanas e se compõem o sistema de cidades. Muitas vezes essas cidades pequenas possuem um papel importante dentro da rede urbana onde estão inseridas, por exemplo, cidades do agronegócio, Elias (2008) atribui que: 
[...]é possível identificar no Brasil agrícola moderno vários municípios cuja urbanização deve-se diretamente à consecução e à expansão do agronegócio, e cuja função principal claramente associa-se às demandas produtivas dos setores relacionados à modernização da agricultura. Nessas cidades, que se caracterizam por serem cidades locais ou que desempenham papéis de intermediação na rede urbana, realiza-se a materialização das condições gerais de reprodução do capital do agronegócio.

Essa contribuição de Elias (2008) e de Wanderley (2001) inquietou-se a desdobrar esses temas para análise no artigo: Cidade de porte pequeno e impactos do avanço do agronegócio para a relação cidade e campo. Adiante analisaremos alguns dados sobre o avanço do setor sucroenergético em três municípios do estado de São Paulo que possuem cidades de porte pequeno, sendo Planalto (4.941hab.), Ubarana (5.910hab.) e José Bonifácio (35.538hab.). Primeiro acentuamos os fatores e processos históricos da constituição do setor no estado de São Paulo e passamos a analisar nosso estudo de caso.

\section{O SETOR SUCROENERGÉTICO NO ESTADO DE SÃO PAULO}

O Sudeste, propriamente o estado de São Paulo recebeu muitos incentivos do Estado para a produção de cana-de-açúcar ao longo dos anos, na década de 70, com a crise do petróleo o seu cultivo passa a ser base da produção de combustíveis, o etanol. A cana-deaçúcar tornou-se uma fonte energética alternativa ao petróleo. Tonin e Tonin (2014, p.64) afirmam que "por sua vez, o etanol emergiu como biocombustível de elevado potencial de produção, devido à existência de vastas terras agricultáveis e clima favorável à produção de sua principal matéria-prima, a cana-de-açúcar”. O incentivo à produção de etanol naquele período também configurou uma forte ajuda ao setor açucareiro, que passava por uma crise com a queda dos preços do açúcar em 1974.

O Proálcool foi estabelecido em 1975 pelo decreto $n^{\circ}$ 76.593. Esse programa, segundo Thomaz Jr. (2002, p.76), tinha o propósito de:

[...] produzir internamente uma alternativa energética própria, contrapondo-se à dependência do petróleo, visando o atendimento do mercado interno e externo e da política de combustíveis automotivos. De acordo com o decreto, a produção do álcool oriundo da cana-de-açúcar, da mandioca ou de qualquer outro insumo deveria ser incentivada por meio da produção agrícola, da modernização e ampliação das destilarias existentes e da instalação de novas unidades produtoras, anexas a usinas ou autônomas, e de unidades armazenadoras. O Programa não se estruturou apenas 
de objetivos oficiais, não se limitando apenas às questões ditas econômicas, como também livrar o país dos gastos crescentes com a importação de petróleo.

Thomaz Jr (2002, p.82), analisando a forma como o Proálcool foi estruturado, ressalta que o programa beneficiou "atores seletos" (que seriam "os grandes proprietários de terras e grandes grupos empresariais e financeiros"), fazendo a base de "profunda exclusão" e "deixando à margem a imensa maioria dos produtores rurais". O Proálcool, segundo Pitta (2011) foi o principal projeto de industrialização da agricultura promovido pela Ditadura Militar no regime de Ernesto Geisel (1974-1979), a julgar pelos créditos subsidiados - cerca de 7 bilhões de dólares até 1990.

O estado de São Paulo se destaca dentro da política do Proálcool, tendo em vista que passou a ser o maior produtor de cana no país. Segundo Girardi e Silveira (2012), São Paulo recebeu $47 \%$ das destilarias anexas e 31,5\% das destilarias autônomas do Brasil. A grande territorialização da cana-de-açúcar em São Paulo ocorreu também por outro programa criado antes do Proálcool - o Instituto do Açúcar e do Álcool (IAA).Na década de 40 foram criadas 49 usinas, dessa forma Girardi e Silveira (2012) expõem que isso possibilitou a consolidação da produção na região de Araraquara e o surgimento das regiões produtoras de Jaú e Vale do Paranapanema. Já na década de 50 e 60 foram criadas 25 usinas para manter o mercado interno. O IAA em 1971 definiu prioritariamente cinco regiões para a produção de açúcar, sendo Ribeirão Preto, Araraquara, Piracicaba, Jaú e o Vale do Paranapanema.

Dessa maneira, os incentivos do Proálcool concentram-se nessas regiões, por serem prioritárias. Com a expansão do Proálcool concentrada nas regiões prioritárias, o estado de São Paulo criou uma política pública para desconcentrar essa expansão - o Pró-Oeste, implantado em 1980. Girardi e Silveira (2012, p.4) afirmam que:

[...] o governo estadual utilizou o PRÓ-OESTE para diminuir a expansão concentradora do cultivo em São Paulo, elegendo regiões do oeste do estado como prioritárias para investimentos e aumento da cultura, sendo selecionadas as regiões de Presidente Prudente, Araçatuba, Bauru e oeste da região de São José do Rio Preto. Foram consideradas de media prioridade a região de Marília e o Centro-Leste de São José do Rio Preto.

O Proálcool foi de grande importância para a expansão e consolidação da produção de cana-de-açúcar em alguns munícipios do estado de São Paulo. Porém, a partir de 1986 o programa do álcool combustível começa a perder força. Segundo Kuperman, Magalhães e Mechado (1992) a motivação especifica para o abono do Proálcool foi a queda do preço do 
petróleo. O barril do óleo cru (árabe-leve) declinou de 26,81 dólares em 1985 para 17,49 dólares em 1987, 15,10 dólares em 1988, 18,20 em 1989 com uma pequena recuperação para 23,07 dólares em 1990.Em 1990, quando Fernando Collor assume a presidência, o Instituto do Açúcar edo Álcool foi extinto e teve início o processo de desregulamentação ao setor. Essa medida assumida por Collor corrobora com os seus objetivos de abertura da economia. De meados da década de 80 até 2003 o setor sucroenergético ficou estagnado, retomando um crescimento significativo somente a partir do início da década de 2000.

No ano de 2003, o Presidente Lula retoma o incentivo ao setor sucroenergético como forma de acelerar o crescimento econômico do país em uma área cujo domínio técnico e o potencial de expansão da produção são muito favoráveis para o Brasil.Também era objetivo do Presidente transformar o etanol em uma commodity, possibilitando a atração de divisas e investimentos para o país. Politicamente o programa estava baseado na intensa discussão internacional sobre o aquecimento climático e necessidade de fontes alternativas ao petróleo, argumentos que o Presidente utilizou em suas inúmeras viagens na promoção do produtor brasileiro. O comprometimento dos diversos países em adicionar agrocombustíveis aos combustíveis fósseis (biodiesel e etanol) permitiram vislumbrar um cenário de forte expansão do mercado para o etanol. O surgimento dos carros flexfuelfoi o principal instrumento de criação de demanda interna. As perspectivas de mercado internacional do etanol não se consolidaram, mas a expansão do mercado interno foi suficiente para uma expansão muito significativa do setor.

O Brasil possuía em 2003, segundo dados do IBGE, em área plantada de cana-deaçúcar, cerca de 5.377.216 ha. Já em 2013, ele passou a ter 10.223.043 ha., isso significa um aumento expressivo de $90 \%$ da área plantada de cana em todo o território nacional, sendo que em dados absolutos chega a 4.845.827 ha. Nesse cenário, o Brasil regressa à política de incentivo ao setor, principalmente via Banco Nacional de Desenvolvimento Econômico e Social (BNDES). A retomada a produção de etanol em grande escala foi favorável, visto o acumulo de experiências com o Proálcool no passado.

O estado de São Paulo é o maior beneficiário das políticas públicas de fomento ao setor sucroenergético, visto que é o maior produtor de cana no Brasil. Segundo dados do IBGE, a área plantada em 2003 era de 2.817.604 ha. e em 2013, dez anos depois, a área plantada chegou a 5.415.013 ha., um aumento de $92 \%$ e de 2.597 .409 em dados absolutos. O estado de São Paulo responde por 53\% de toda área plantada de cana no Brasil. Segundo a 
CONAB (2014) espera-se que na safra 2015/16 o estado de São Paulo possua 4.685.7 de área plantada. Referente à produção industrial de açúcar, o estado alcançará cerca de 48.353.288 toneladas. Em etanol anidro, esse misturado na gasolina, São Paulo produzirá cerca de 6.804.689 litros e de etanol hidratado, usado nos carros diretamente, aproximadamente 6.807.141 litros. Os dados apresentados evidenciam como o agronegócio canavieiro é dominante no espaço agrário paulista.

\section{O SETOR SUCROENERGÉTICO NOS MUNICÍPIOS DE JOSÉ BONIFÁCIO, UBARANA E PLANALTO: IMPACTOS E A RELAÇÃO CIDADE E CAMPO.}

Os municípios selecionados para o estudo fazem parte da microrregião de São José do Rio Preto ( Figura 01), isso se dá, pois é uma das microrregiões paulistas na qual houve maior expansão recente da cana-de-açúcar. Girardi e Silveira (2012), ao analisarem os dados da evolução da área plantada de cana nas microrregiões paulistas, constataram que:

\footnotetext{
[...] em 29 delas 50\% ou mais da área plantada foi expandida no período 2000-2010, sendo essas regiões responsáveis por $49,5 \%$ da área plantada de cana-de-açúcar no estado. Isso quer dizer que ao menos $1 / 4$ da evolução verificada na década de 2000 ocorreu em regiões não tradicionais. Em ordem de área plantada, as principais dessas 29 microrregiões são São José do Rio Preto, Presidente Prudente, Araçatuba, Birigui, Andradina, Bauru e Lins (GIRARDI e SILVEIRA, 2012, p.6),
}

A microrregião de São José do Rio Preto tinha em 2003 cerca de 107.647 ha. plantados de cana e no ano de 2013 a área total era de 409.116 ha. - um aumento interno de 301.469 ha e $280 \%$. O aumento verificado na microrregião representou $11 \%$ do aumento total no estado de São Paulo e 6\% do aumento total no Brasil. A participação dos três municípios selecionados na evolução do total da área plantada com cana-de-açúcar na microrregião de São José do Rio Preto entre 2003-2013 é a seguinte: José Bonifácio com 28\% (29.900 ha); Planalto com 9,1\% (9.840 ha) e Ubarana com 6,3\% (6.878 ha).

Em José Bonifácio, a empresa responsável pelo setor sucroenergético é o Grupo Virgolino de Oliveira. Segundo o site da empresa, a unidade de José Bonifácio iniciou suas atividades em 2006. Posteriormente, em 2008, expandiu suas instalações aumentando a sua capacidade de produção. Ainda segundo o site a capacidade produção anual é da seguinte ordem: moagem: 3.700 .000 toneladas, produção de açúcar de 242.000 a 381.000 toneladas e de produção de etanol de 87.000.000 a 174.000.000 litros. 
Figura 01: Localização dos municípios de José Bonifácio, Planalto e Ubarana

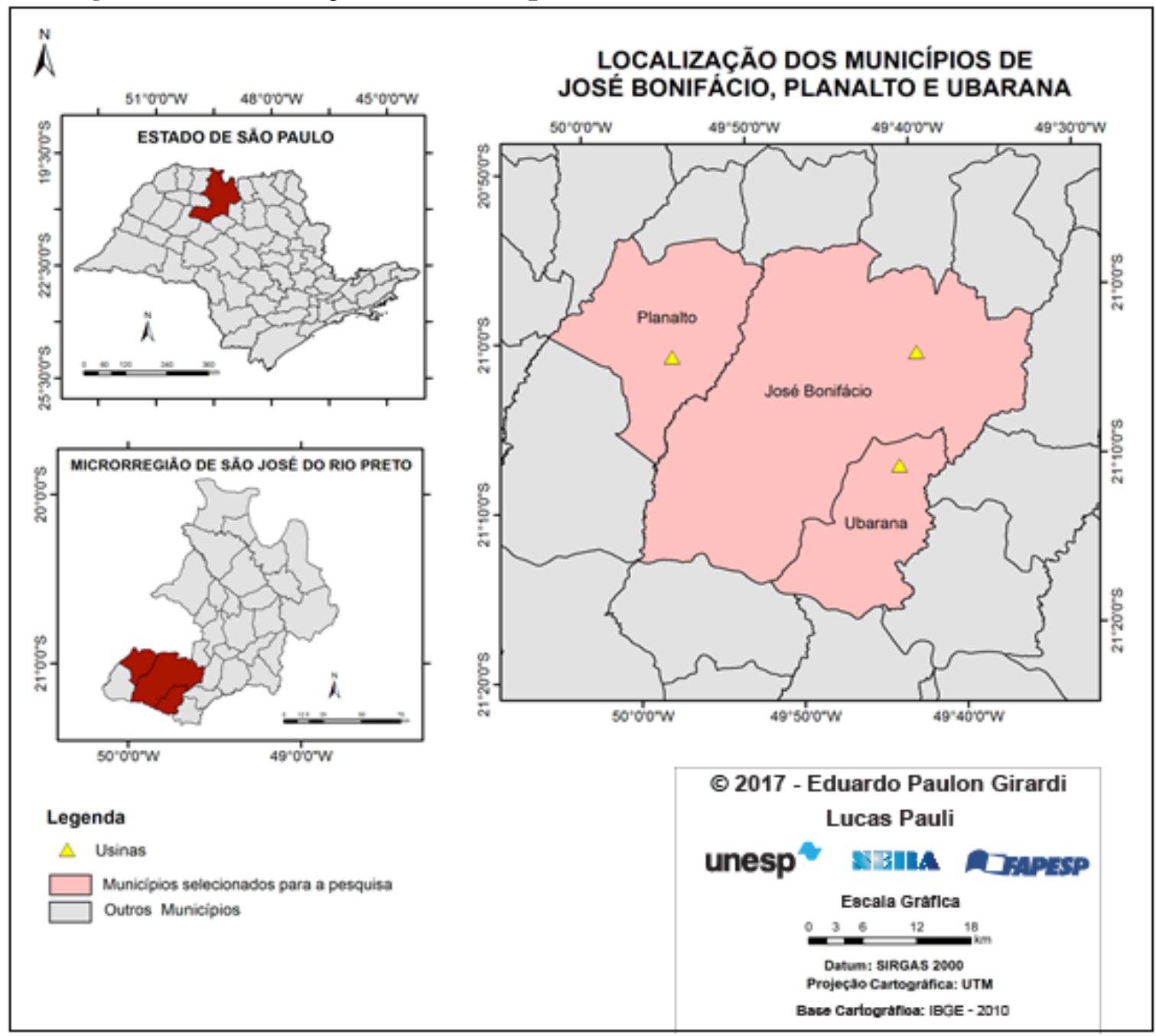

No município de Planalto, o Grupo Moreno é proprietário da usina Coplasa Açúcar e Álcool Ltda., cujo funcionamento teve início no ano de 2006. Segundo o site da empresa, a capacidade de moagem diária da usina é de 24.000 mil toneladas de cana, a capacidade de produção de açúcar é de 45.000 sacas de $50 \mathrm{~kg}$ dia e de $1.200 \mathrm{~m}^{3}$ de etanol por dia. Segundo o Anuário da Cana (2013), a unidade moeu 2.377.084.00 toneladas de cana, produziu 118.839.00 $\mathrm{m}^{3}$ de etanol e 129.173.00 toneladas de açúcar no ano de 2013.

Já em Ubarana, o Grupo Ruette é responsável pela usina Monterrey, cujas atividades tiveram início no ano de 2008. Porém no ano de 2015, a usina foi vendida ao grupo de investimentos Black River, subsidiaria da Cargill. Segundo o site do grupo, a usina tem capacidade de produção de 180 toneladas de açúcar e 200 milhões de litros de etanol por 
safra. Segundo o Anuário da Cana (2013), a usina tem capacidade de moagem de cerca de 682 mil toneladas de cana-de-açúcar, sua área plantada segundo o anuário é 13.500 mil hectares e destina-se $100 \%$ para produção de etanol anidro, sua produção de etanol no ano de 2013 chegou a 75.476.16 $\mathrm{m}^{3}$.Os três municípios selecionados para o estudo receberam a implantação de usinas a partir de 2006 via expansão recente do setor sucroenergético. Salientamos que essa expansão do setor influencia em novas relações entre campo e cidade, selecionamos alguns dados para expressar esses processos contidos no quadroabaixo.

\section{Quadro 1 - Evolução de alguns indicadores econômicos e sociais nos municípios paulistas de José Bonifácio, Planalto e Ubarana.}

\begin{tabular}{|c|c|c|c|}
\hline & JOSÉ BONIFÁCIO & PLANALTO & UBARANA \\
\hline $\begin{array}{l}\text { Participação na evolução da área plantada com } \\
\text { cana-de-açúcar entre as safras } 2003 / 2004 \\
2011 / 12 \text { sobre a área total plantada na safra } \\
2011 / 12(\%)\end{array}$ & $94 \%$ & $78 \%$ & $69 \%$ \\
\hline $\begin{array}{l}\text { Área do município plantada com cana-de- } \\
\text { açúcar na safra 2011/2012 (\%) }\end{array}$ & $35,9 \%$ & $46,5 \%$ & $46,9 \%$ \\
\hline $\begin{array}{l}\text { Porcentagem de migrantes na população em } \\
2010 \text { (pessoas com menos de } 10 \text { anos de } \\
\text { residência no município) }\end{array}$ & 19,2 & 26,9 & 23,4 \\
\hline População total em 2015 & 35.538 hab. & 4.941 hab. & 5.910 hab. \\
\hline Evolução da população total 2000-2010 (\%) & $14,1 \%$ & $21,6 \%$ & $25,3 \%$ \\
\hline $\begin{array}{l}\text { Evolução da população urbana } \\
20002010(\%)\end{array}$ & $18,6 \%$ & $33,1 \%$ & $27,1 \%$ \\
\hline Evolução da população rural 2000-2010 (\%) & $-16,7 \%$ & $-17,1 \%$ & $8,6 \%$ \\
\hline Evolução da massa salarial 2003-2011 (\%) & $138,29 \%$ & $282,15 \%$ & $202,69 \%$ \\
\hline Evolução do salário médio 2003-2011 (\%) & $36,35 \%$ & $103,82 \%$ & $71,49 \%$ \\
\hline $\begin{array}{l}\text { Evolução dos vínculos empregatícios } \\
\text { 2003-2011(\%) }\end{array}$ & $74,8 \%$ & $87,5 \%$ & $76,5 \%$ \\
\hline Evolução do PIB municipal 2003-2011 (\%) & $43,61 \%$ & $57,26 \%$ & $52,42 \%$ \\
\hline Evolução do rebanho bovino 2003-2011 (\%) & $-45,7 \%$ & $-60,7 \%$ & $-57,7 \%$ \\
\hline $\begin{array}{l}\text { Evolução da área de culturas temporárias exceto } \\
\text { cana-de-açúcar 2003-2011(\%) }\end{array}$ & $-24,9 \%$ & $-67,9 \%$ & $-38,9 \%$ \\
\hline $\begin{array}{l}\text { Evolução da área de culturas permanentes } \\
\text { exceto cana-de-açúcar 2003-2011 (\%) }\end{array}$ & $-14,8 \%$ & $-44,9 \%$ & $-45,5 \%$ \\
\hline $\begin{array}{l}\text { Evolução da porcentagem da renda do quinto } \\
\text { mais pobre } 2000-2010(\%)\end{array}$ & $71,57 \%$ & $108,38 \%$ & $64,99 \%$ \\
\hline
\end{tabular}

Fonte: SIDRA (IBGE) e CANASAT

Atenta-se que os municípios em questão, na rede urbana são considerados como cidades de pequeno porte (JURADO DA SILVA; SPOSITO, 2009), e que essas mudanças demográficas afetam os equipamentos públicos, gerando aumento da demanda por saúde e 
educação e também desencadeiam aumento na procura por habitação, podendo levar ao aumento da especulação imobiliária, visto como o campo influencia na cidade e vice e versa.

Ainda sobre cidades de pequeno porte, que devem ser conceituadas para além da dimensão demográfica, Bacelar (2010) coloca que as funções exercidas na rede urbana e a diversidade econômica são elementos a se considerar para definir o porte da cidade, então, a sua importância se dá a partir dos bens e serviços que é cidade pode oferecer dentro da rede, em suma a teoria dos lugares centrais de Walter Christaller é importante para compreender a realidade das cidades pequenas dentro da rede urbana brasileira. Bacelar (2010, p.6) sintetiza de forma clara o contexto das cidades pequenas no Brasil, principalmente aquelas com o agronegócio latente.

\begin{abstract}
No período pós década de 1970, o período técnico-científico-informacional, a urbanização maciça cria dois 'Brasis', um urbano e outro agrícola e não mais aquela dicotomia observada na década de 1950 onde os dois 'Brasis' eram um urbano e outro rural (SANTOS, 1996 e 2001). O Brasil agrícola insere cidades que se articulam em um espaço de produção agrícola modernizado, que evidencia um padrão de urbanização diferencial, em que a vida nas cidades integra-se ao mundo agrícola, não apenas rural, e não totalmente ao mundo urbano. Desse modo, é também evidência de que no campo modernizado ocorre a expulsão do trabalhador não qualificado, pois as relações de trabalho não são mais rurais e sim urbanas, tais como carteira de trabalho, a assinatura do ponto, cestas básicas etc. O campo perde população, mas também, e nessa nova configuração, as pequenas cidades perdem população.
\end{abstract}

Analisando os dados organizados sobre os três municípios elegidos, a primeira informação do quadro representa que a expansão recente (a partir de 2003) da área plantada com cana-de-açúcar representa a maior parte da área plantada em 2012. Destaque para José Bonifácio, com $94 \%$ de representatividade. Sobre a porcentagem da área total do município cultivada com cana na safra 2011/12, Planalto e Ubarana possuíram maior relevância com $46,5 \%$ e 46,9\%, embora José Bonifácio tenha o dobro do tamanho desses dois municípios. No tocante à questão demográfica, a porcentagem de migrantes em 2010 são altas: 19,2 \% em José Bonifácio, 26,9 em Planalto e 23,4\%. Já na evolução da população total em 2000-2010, José Bonifácio apresentou 14,1\%, Planalto 21,6\% e Ubarana 25,3\%. Sobre a evolução da população urbana entre 2000 e 2010, José Bonifácio alcançou 18,6\%, Planalto 33,1\% e Ubarana $27,1 \%$.

Outro impacto que parece estar relacionado com a evolução do setor sucroenergético nos municípios selecionados é o êxodo rural, pois a evolução da população rural entre 20002010 foi negativa em José Bonifácio com -16,7\%, e Planalto com -17,1\%. Contudo, em 
Ubarana houve aumento de 8,6\%, indica-se que esse aumento se dá por vários elementos, como buscar por trabalho.

Sobre o PIB, o município que apresentou maior aumento foi Planalto com 57,26\%, seguido de Ubarana, com 52,42\% e José Bonifácio, com 43, 61\%. Na evolução de vínculos empregatícios entre 2003 e 2011, Planalto teve maior evolução (87,5\%), seguido de Ubarana com 76,5\% e Planalto com 74,8\%. Referente à massa salarial no período de 2003-2011, Planalto demostrou maior evolução no período com 282,15\%, depois Ubarana com 202, 69\% e José Bonifácio com 138, 29\%. Sobre a renda, a evolução da porcentagem do quinto mais pobre entre 2000 e 2011, Planalto apresentou maior elevação, com 108,38\%, seguido de José Bonifácio, com $71,57 \%$ e Ubarana $64,99 \%$. Este aumento pode refletir na cidade com aumento do consumo dos citadinos.

Referenteà produção agrícola temporária e permanente e o rebanho bovino, todos os municípios apresentaram quedas expressivas na evolução do período de 2003- 2011 o que indica ser fruto do processo de territorialização da cana-de-açúcar. Como pode ser visto nos dados apresentados, o setor sucroenergético causou impactos muito importantes nos municípios selecionados.

Para além dos dados econômicos e sociais apresentados, outro impacto ambiental ${ }^{3}$ também causado pelo setor sucroenergético que reverbera tanto no campo como na cidade, é a aplicação da vinhaça ${ }^{4}$ de forma indevida na forma de adubo no município de Planalto, isso causa o aumento da proliferação de uma espécie de mosca muito nociva à saúde dos animais e seres humanos, que é a mosca do estábulo ou mosca do bagaço (Stomoxyscalcitrans ).Essa espécie de moscas pode causar a morte de bovinos e até diminuir a produção de leite.

Segundo a notícia e a partir de trabalhos de tampo, os citadinos indignados atribuem que com o aumento da temperatura faz com que o contingente de moscas cresça, fazendo que os animais domésticos sofram muito, principalmente os cachorros. Já no campo, alguns pecuaristas acusam uma diminuição do rebanho, pois as moscas influenciam no ganho de peso dos animais.

\footnotetext{
3 http://g1.globo.com/sao-paulo/sao-jose-do-rio-preto-aracatuba/noticia/2016/07/moscas-invadem-areas-rural-eurbana-e-atacam-animais-em-planalto.html.

${ }^{4}$ Resíduo pastoso e malcheiroso que resta após a destilação fracionada do caldo de cana-de-açúcar (garapa) fermentado, para a obtenção do etanol (álcool etílico)
} 


\section{CONSIDERAÇÕES FINAIS}

Diante do processo apresentado pontuamos que o avanço setor sucroenergético causa impactos tanto na cidade como no campo. Referente ao estudo de caso, as cidades de pequeno porte os efeitos da expansão do setor sucroenergético são mais latentes, tanto na estrutura dos espaços e na dinâmica social. O setor sucroenergético impõem também o processo de urbanização dessas cidades e consequentemente o crescimento, tanto na extensão territorial e na oferta de bens e serviços.

Também acrescentamos uma carência conceitual quanto o conceito de cidade de pequeno porte, como afirmado em Wanderley (2001, p.2) "No entanto, a pesquisa sobre os pequenos municípios parece permanecer à margem do interesse dos pesquisadores, sem que se formule sobre eles uma reflexão mais sistemática.”. Entretanto, muitas pesquisas sobre a relação cidade e campo e cidades do agronegócio vem colocando os assuntos sobre cidades de pequeno porte como importantes para a compreensão dos processos apresentados, como visto em Elias (2008)

Enfatizamos que a relação cidade e campo no atual estágio de expansão do agronegócio via promoção de Estadoé conflituosa e apresentam diversas nuances em cada parte do Brasil, com isso devemos levar em conta as especificidades de cada espaço/regiãopara uma melhor análise do objeto estudado. Então, o que se reafirma é uma questão agrária que está para além dos problemas engendrados no campo e transbordando, também, para o urbano, como no estudo de caso apresentado.

\section{REFERÊNCIAS}

ABRAMOVAY, R. Funções e medidas da ruralidade no desenvolvimento contemporâneo. Texto para discussão, n 722. Rio de Janeiro, 2000. 31p.

ALENTEJANO, P.R. As relações campo - cidade no Brasil do século XXI. Terra Livre, V.2, no 21 , p. $01-22.2003$.

ALVES, F. D. A relação campo-cidade na Geografia Brasileira: apontamentos teóricos a partir de periódicos científicos. Geografia. Ensino \& Pesquisa (UFSM), v. 16, p. 7-18, 2012. 
BACELAR, W. K. A.. Pequena cidade: caracterização e conceituação pelo ponto de vista político-administrativo. In: XVI ENCONTRO NACIONAL DE GEÓGRAFOS, 2010, Porto Alegre. XVI Encontro Nacional de Geógrafos - anais, 2010. v. 0. p. 0-0.

DELGADO, G. da C. Capital financeiro e agricultura no Brasil, 1965 -1985. Campinas: Leone; Unicamp, 1985.

ELIAS, D. Redes agroindustriais e urbanização dispersa no Brasil. $\mathbf{X}$ Coloquio Internacional de geocritica, 2008.

JURADO DA SILVA, P. F. \& SPOSITO, E. Discussão geográfica das pequenas cidades. Geografia. Associação de Geografia Teorética. V. 34, N. 2. Rio Claro, mai/ago, 2009.

GIRARDI. E.P; SILVEIRA, M. B. F. da. Mapeamento da territorialização do cultivo de canade-açúcar no estado de São Paulo no período 2000-2011. XVII Encontro Nacional de Geógrafos. 17, 2012, Belo Horizonte. Anais do XVII Encontro Nacional de Geógrafos. Belo Horizonte: AGB, 2012.

GRAZIANO DA SILVA, J. A nova dinâmica da agricultura brasileira. Campinas: Unicamp- Instituto de Economia, 1996.

HOUTART, F. Agroenergia: solução para o clima ou saída da crise para o capital?

Petrópolis: Vozes, 2010.

HESPANHOL, A.N; HESPANHOL, R. A. M. Dinâmica do espaço rural e novas perspectivas de análise das relações campo-cidade no Brasil. Terra Livre, v. 2, p. 133-148, 2006.

HESPANHOL, R.A.M. Campo e cidade, rural e urbano no Brasil contemporâneo. Mercator (Fortaleza. Online), v. 12, p. 103-112-112, 2013.

KUPERMAN, N; MACHADO, J.P.A e MACHADO,). Proálcool, uma avaliação global.,Rio de Janeiro, XenonLtda, 1992.

LOCATEL, C. D. Da dicotomia rural-urbano à urbanização do território no brasil. Mercator(fortaleza. Online), v. 12, p. 85-102-102, 2013

MAPA - MINISTÉRIO DA AGRICULTURA, PECUÁRIA E ABASTECIMENTO. Plano nacional de agroenergia - 2006-2011. Brasília: Mapa, 2006.

MARTINS, J. de S. A militarização da questão agrária no Brasil. Petrópolis, RJ: Editora Vozes, 1985.

PITTA, F.T. Modernização retardatária e agroindústria sucroalcooleira paulista: o Proálcool como reprodução fictícia do capital em crise. 2011. 184 f. Dissertação (Mestrado em Geografia) - Faculdade de Filosofia, Letras e Ciências Humanas da Universidade de São Paulo, São Paulo 
OHASHIA, F.H. O advento, crescimento, crise e abandono do Proálcool. 2008. 46 f. Monografia apresentada no curso de Ciências Econômicas da Universidade Estadual de Campinas como parte dos requisitos para completar o curso de graduação, Campinas.

SANTOS, M. e SILVEIRA, M. O Brasil. Território e sociedade no início do século XXI. Rio de Janeiro: Record, 2001, p. 268-269.

SANTOS, M. A urbanização Brasileira. São Paulo: Hucitec, 1993.

SOROKIN, P.; ZIMMERMAN, C; GALPIN, C. Diferenças fundamentais entre o mundo rural e o urbano. IN: MARTINS, J.S. Introdução critica a Sociologia Rural. SP. Hucitec, p. 198-224. 1986.

SPOSITO, M.E.B; WHITACKER, A.M (Org).Cidade e campo - Relações e contradições entre urbano e rural. SP. Expressão Popular. 2006 (Geografia em Moviemento).

SZMRECSÁNYI, T. O planejamento da agroindústria canavieira no Brasil (1930- 1975). São Paulo: Hucitec/UNICAMP, 1979.

TONIN, R.T; TONIN, J.M. Do Proálcool ao "Próetanol": novos desafios na produção do etanol brasileiro. Informe Gepec, Toledo, v. 18, n. 1, p. 61-76, jan./jun. 2014.

THOMAZ JÚNIOR, A. Por trás dos canaviais os (nós) da cana: relação capital x trabalho e o movimento sindical dos trabalhadores na agroindústria canavieira paulista. 1. ed. São Paulo: Annablume/FAPESP, 2002.

VEIGA, J. E. Cidades imaginárias: o Brasil é menos urbano do que se calcula. Campinas: Autores Associados, 2002, 212 p.

WANDERLEY, M.N. A ruralidade no Brasil moderno. Por um pacto social pelo desenvolvimento rural. IN: GIARRACCA, N. (Org). Uma nueva ruralidade en América Latina? Bueno Aires, p 32 - 44. 2001.

. Urbanização e ruralidade: relações entre a pequena cidade e o mundo

rural, estudo preliminar sobre os pequenos municípios em Pernambuco. Recife, 2001. 27p.

O mundo rural brasileiro: acesso a bens e serviços e integração campo-

cidade. Estudos Sociedade e Agricultura. Ano 17, v. 01. 62 - 85. 2009.

Recebido em Abril de 2017

Aprovado em Junho de 2017

Publicado em Agosto de 2017

Sociedade e Território - Natal. Vol. 27, N. 3, p. 123 - 141.Jan./Jun. de 2017 